\title{
Performing Management in School Organizations and Entrepreneurship
}

\author{
Postiniuc (Onișoru) Georgiana Florența* and Mănescu (Dragomir) Daniela
}

Valahia University of Târgoviște, Romania

\section{ARTICLE INFO}

\section{Keywords:}

Management

Strategy

Education

Entrepreneurship

Performance

\begin{abstract}
In the specialized literature there is no unitary opinion regarding the definition of efficient management and managerial performance. For the managers of the Romanian organization, subject to multiple and increasingly complex contextual and endogenous challenges and prone to informational "claustrophobia" due to the volume of information that must be decisively capitalized, the effectiveness of their performance is much more important.

A first factor that influences the level of managerial performance is the competence of those who exercise the management processes, respectively of the managers, but also of those who operationalize the decisions, i.e., of the subordinates.

The managerial activity carried out by the principals and deputy principals of the pre-university education units is evaluated following certain components and attributions from the job description according to some performance criteria.

The research aimed to analyze the performance criteria and the influence of the manager on the performance criteria in the case of management staff in a school organization. The most important criterion is the design of the coordination strategy and directions for the development of the educational unit, and the least important is the monitoring / evaluation / control of the activities in the educational unit. The conclusion of contracts with economic agents, NGOs and other organizations regarding the development of projects was evaluated negatively by the majority of respondents, as it has no influence on the increase of performance.

The management of the school must play a catalytic role among teachers, in the sense of promoting, identifying, stimulating and rewarding creative teachers who participate in forming a positive image and increasing the prestige of the school in the community by creating its own organizational culture.
\end{abstract}

\section{Introduction}

Management is an integrative science, which has taken from all the research fields results that can contribute to the improvement of work performance and satisfaction of those working in a social organization, as well as to ensuring a competitive advantage for the respective organization.

In the specialized literature there is no unitary opinion regarding the definition of performance management and managerial performance.

A truly efficient and effective management, performance, performed by professional managers is the main "supplier" performance in "zones" which they lead. Thus, a question arises: "Which of the two notions represents a more important indicator for managerial performance, efficiency or effectiveness?"

For the managers of the Romanian organization, subjected to multiple and increasingly complex contextual and endogenous challenges and predisposed to informational "claustrophobia" due to

\footnotetext{
* Corresponding Author E-Mail Address: gonisoru@gmail.com 
the volume of information to be used decisively, the effectiveness of their performance is more important.

The effectiveness is materialized in obtaining general and specific managerial performances, (I. Verboncu, 2005).

Given the degree of effectiveness, between the educational institutions, a series of differences appear that are due to the influence of some organizational factors identified by Purkey \& Simth (1983) and process factors later identified by Fulan (1985) as the following:

1) focusing the leadership concern on the curriculum;

2) Climatically stimulating inside the school unit;

3) Focus on curriculum and teaching (from the perspective of curriculum implementation);

4) Clear goals and high expectations from students;

5) A functional system for monitoring student progress;

6) Permanent concern for the development of school staff;

7) Active involvement of parents in school life, with stimulating value;

8) Supporting the school from the superordinate management structures;

9) A values system with the role of directing members of the school organization;

10) The existence of an intense interaction and communication between the members of the organization, both horizontally and vertically.

The strategy of an organization is represented by its long-term objectives and the tactics used to achieve these objectives (Jex, 2002). The following section briefly presents the main entrepreneurial strategies that influence performance, with an emphasis on the management and resources of the school organization.

\section{Entrepreneurial Strategies that Influence the Management of the School Organization}

\subsection{Factors Influencing the Growth of School Organization Performance}

Edmonds (1979) identified the following five factors that, in his opinion, are correlated with the performance of effective schools:

$\checkmark$ strong management and attention paid to the quality of education;

$\checkmark$ high expectations regarding the performance of all students;

$\checkmark$ safety and order (favorable learning environment);

$\checkmark$ emphasis on teaching the basic disciplines (reading, writing, mathematics);

$\checkmark$ assessments and frequent monitoring of student progress.

Achieving effective management will be influenced by the conduct and practice of each manager, his leadership style and personality, said Alois Gherghuț (2007). The efficiency of the managerial act will be positively influenced by "the flexibility, the openness to the new, the flexibility of the organization structure, the specialized and individualized approach to the problems". Thus, "the managerial act in the field of educational services becomes a complex and specialized activity that demands a series of personal qualities that make a manager a brand specialist in his field".

The managerial activity in the school is based on a system of coordination methods and tools necessary to reach predetermined quantitative and qualitative standards, the large number of unforeseen phenomena makes it necessary to adopt innovative strategies, based on the intuition, spontaneity, inventiveness and originality of the school managers. Thus, a first factor that influences the level of managerial performances is the competence of those who exercise the management processes, respectively of the managers, but also of those who operationalize the decisions, that is, the subordinates. 


\subsection{Management of the School Organization}

School management represents, in the current period, a continuous challenge, which can be led to a high performance only if the designated persons take into account the complex functionality required of a school, know and apply a knowledge system in the science of the management, if they are able to use a number of techniques and methods that provide educational process consistency tert complicated, dynamism and efficiency. This is not enough life experience, it is also necessary a process of instruction in the art of school and educational management.

In any organization, management has a hierarchical structure, on levels of "management". Usually, every organization has, from a management point of view, a pyramidal construction. At the top of the pyramid are top or top management (organization management, director), middle management (committee heads) and basic management (student class management).

Every school organization is growing and therefore the methods of recruiting and employing people with the required skills must be established. This is usually reflected in a form of human resource planning. Analyzing the future projects and trends of the organization - through a project of institutional development (PDI), it is estimated the number of people that is needed and the type of skills and competences that the eventual vacancies require.

From this perspective, we consider it necessary to emphasize that the school manager exercises at the same time managerial functions with sequential and consecutive action, focused on complex dimensions such as: analysis, diagnosis, organization, design, planning, implementation of programs (operational management, control, evaluation). the final).

At the same time the managerial functions are centered on the human dimension, with concrete activities such as: organizing groups, forming teams; professional orientation of students, mentoring of teachers, motivating people, participation, personal development of team members; negotiation; conflict prevention and resolution etc. all of which are included in the institutional development project.

Harrington, HJ (2000) says: "Every aspect of the activity of an organization is determined by the competences, motivation and efficiency in the organization of the personnel. Of all the tasks of management, the management of the human component is the most important because it depends on how well everything is done in an organization."

The institutional development project is a strategic managerial tool of the director, focused on change, innovation and development in structural and functional level, coordinating the activities and focusing on the purposes of education.

Within the strategy elaborated, the roles and responsibilities of the main institutions, groups and key persons in the school and outside it must be specified: what is the role of the director, of the board of directors and of the professional council, of the teachers of different specialties, of the parent committee, of the local government etc. Expected results also work as performance indicators of the whole strategy; if the results established in the project (PDI) are obtained, it means that the strategy has been successfully implemented. The development and drafting of the institutional development project involve an approach whose success is dependent on the observance of certain phases or stages. Writing, promoting, coordinating, monitoring, evaluating and sustainability are activities of the utmost importance, whose responsibility lies mainly with the top management (top management) of each school organization.

Ogbonna \& Harris, 2000, conducted a research in the field of organizational culture, showing that bureaucratic and instrumental leadership styles have a negative impact on performance while supportive leadership styles have a positive impact. These effects are mediated by the form of organizational culture. Innovative (accept risk) and competitive (goal-oriented) cultures have a positive impact while bureaucratic (foreground) and community (as an extended family) have a negative impact on performance.

Aydin's study (2012) analyzed the impact of three theories (McGregor, 1960; McGregor, 1967) regarding management style on research performance: theory X (autocratic style, assumes that 
employees will not work), theory Y (transformational style, which decentralizes responsibility and increases autonomy, assumes that employees have the same goals as their bosses) and the $\mathrm{Z}$ theory (hybrid style, similar to the Japanese one, which emphasizes skill building and lifelong learning). The results of the study show that the first management style (theory $\mathrm{X}$ ) negatively affects the research performance while the other two styles have a positive effect. As the author points out, the results should not be generalized in all situations, considering the individual needs and differences.

The factors that contribute to the high performance are associated with the management at the department level: clear research objectives and directions, collegial departmental culture, common values, openness to change, availability and effort to increase the performance, communicating the organization's initiatives.

For the prediction of performance, the most useful indicator is competence. For intervention in order to improve performance, all competences can be used, but the most useful indicator is learning competence. The predictors of managerial success are constituted in a constellation, in which some have been better studied, others just aware and taken into account (moral and emotional intelligence), and some not at all (systemic intelligence). All these predictors can be measured indirectly through managerial competencies.

Entrepreneurship in the management of the school organization brings positive influences because the entrepreneur is characterized by concepts such as creativity, innovation, his ability to react quickly and efficiently to new business opportunities, flexible, easily adapts to change, has the desire for success for all departments, his take risks without hesitation; indicators related to the desire to create something out of nothing. The manager is characterized by concepts such as order, organization, procedures, and so on, indicating a desire to organize and maintain what exists.

Entrepreneurship contains a good dose of management. But entrepreneurship and management are not synonymous. Entrepreneurship involves specific management, with its own concepts, goals and methods. It is based on risk management and not on minimizing it, focusing on opportunities and not on resources, on action and not on analysis, on an informal, flexible management structure and not on a formal one. These characteristics also derive from the specific characteristics of the contractor.

Entrepreneurship influences can be observed in managerial activity at the level of a small number of school organizations. These are easily recognizable due to the desire for continuous development, to develop new projects.

\subsection{Annual Evaluation of Managerial Activity}

The managerial activity carried out by the directors and deputy directors of the pre-university education units, is evaluated annually, according to a methodology developed by the Ministry of National Education and Research (MENC). The annual evaluation of the managerial activity carried out by the directors and the deputy directors of the state educational units is carried out by the school inspectorate.

Based on the framework sheets approved by the MENC, the school inspectorates will elaborate / revise at the beginning of the school year the (self) evaluation sheet for the director / deputy director of the pre-university education units and, with the approval of the school inspectorate's board of directors, may introduce new criteria. performance, the scores in the (self) evaluation sheet being reallocated according to the specific of the educational unit (level of education, sector, special education, educational alternatives). This evaluation is finalized by granting an annual rating or for the period related to the exercise of the management position.

The managerial activity carried out by the directors and deputy directors of the pre-university education units is evaluated by following certain components and the attributions in the job description according to performance criteria. 
The components pursued in the evaluation of the managerial activity are the following:

1. Designing the coordination strategy and directions for the development of the educational unit

2. Organization of the activities of the educational unit $t$

3. Managing / coordinating the activity of the educational unit

4. Motivation / training staff of subordinate

5. Monitoring / evaluation / control of the activities in the educational unit

6. Relations of communication

\section{Analysis of The Relationship Between Manager's Attributions and Performance Management in the School Organization}

\subsection{Methods}

The objective of the research was to analyze the performance criteria and the influence of the manager on the performance criteria in the case of the management staff in a school organization. The empirical study was carried out by applying the survey method based on the questionnaire. Items were measured on the Likert scale, with 5 degrees of intensity ( 1 "very small", 5 "very large"). The questionnaire and the respondent can indicate and evaluate managerial attributions (beyond those already mentioned you) who deem relevant 're for improving the efficiency of business management.

The target population was aimed at the principals of the school units from pre-university education, respectively the personnel who perform management and / or execution functions. Data were collected through self-administered questionnaires in January 2020 . 281 questionnaires were collected. After eliminating the questionnaires with missing data, a sample of 230 persons was obtained.

\subsection{Results and Discussions}

Through performance management in school organization means that staff performance conducere. Table 1 shows the performance criteria were considered in this study, grouped into seven categories: proiectarea coordination strategy and directions of development of the school, arganizarea activities of the school, conducerea / coordination of activity unit education, motivation / training of subordinate staff, monitoring / evaluation / control of activities in the educational unit, communication relationships, professional retraining. In the first column is the acronym used in the table of results.

Table 1. Performance criteria

\begin{tabular}{ll}
\hline cronym & Component evaluated \\
\hline POI & $\begin{array}{l}\text { Predesigning the coordination strategy and directions for the development of the } \\
\text { educational unit }\end{array}$ \\
\hline WOW & Organizing the activities of the educational unit $t$ \\
\hline DIR & Conducting / coordinating the activity of the educational unit \\
\hline MOT & Motivating / training subordinate personnel \\
\hline EV & The monitoring / evaluation / control of the activities in the educational unit \\
\hline COM & Relations of communication \\
\hline PP & Professional retraining
\end{tabular}

Source: by the author

The level of importance of the performance criteria, by performance categories, is shown in Figure 1. In general, the management staff appreciated the importance of being large and very large. As can be seen, the most important criterion is the design of the coordination strategy and directions for the development of the educational unit, with 200 respondents who gave the highest value to this component, followed by the organization of the activities of the education unit, the professional training and the coordination of the activity of the organization of education. 


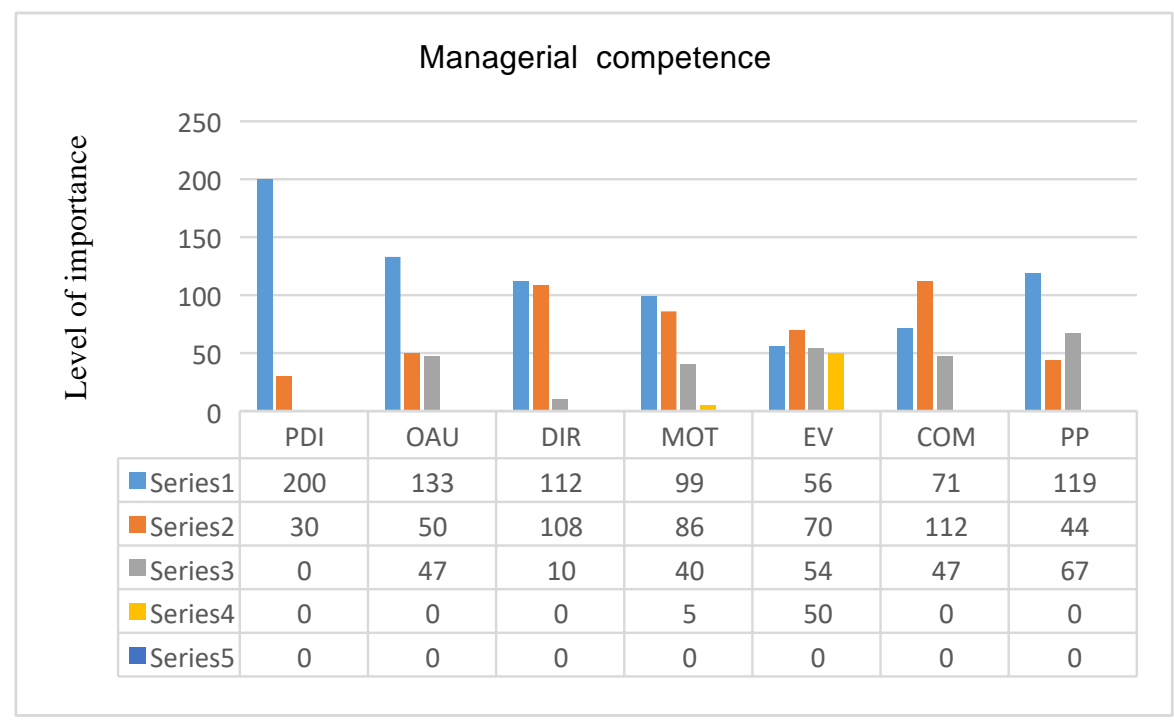

Figure 1. The level of importance of the performance criteria Source: by the author

Following, as an order of importance, the coordination of the activity of the educational unit (DIR), the communication and the evaluation. Of less importance is the monitoring/ evaluation/ control of the activities in the educational unit.

\subsection{Manager Influence on Performance of Organization}

Table 2 presents the role of the manager of the school organization, regarding the second component of the evaluation sheet, on the performance increase.

Table 2: Organization of the activities of the educational unit

\begin{tabular}{ll}
\hline Acronym & Manager's duties \\
\hline FP & It compiles, according to the law, the job descriptions for the subordinate staff \\
\hline ANG & $\begin{array}{l}\text { Responsible for the selection, hiring and termination of employment relationships of the staff in } \\
\text { the unit, as well as for the selection of non-teaching staff }\end{array}$ \\
\hline MOB & $\begin{array}{l}\text { It fulfills the attributions provided by the normative acts in force regarding the mobility of the } \\
\text { teaching staff }\end{array}$ \\
\hline AUT & $\begin{array}{l}\text { Coordinates the process of obtaining the authorizations and legal approvals necessary for the } \\
\text { functioning of educational units }\end{array}$ \\
\hline CP & $\begin{array}{l}\text { The conclusion of contracts with the economic agents, NGOs and other organizations regarding } \\
\text { the development of projects }\end{array}$ \\
\hline PPUE & $\begin{array}{l}\text { Launches partnership projects with similar educational units in the European Union or other areas } \\
\end{array}$
\end{tabular}

Source: by the author 


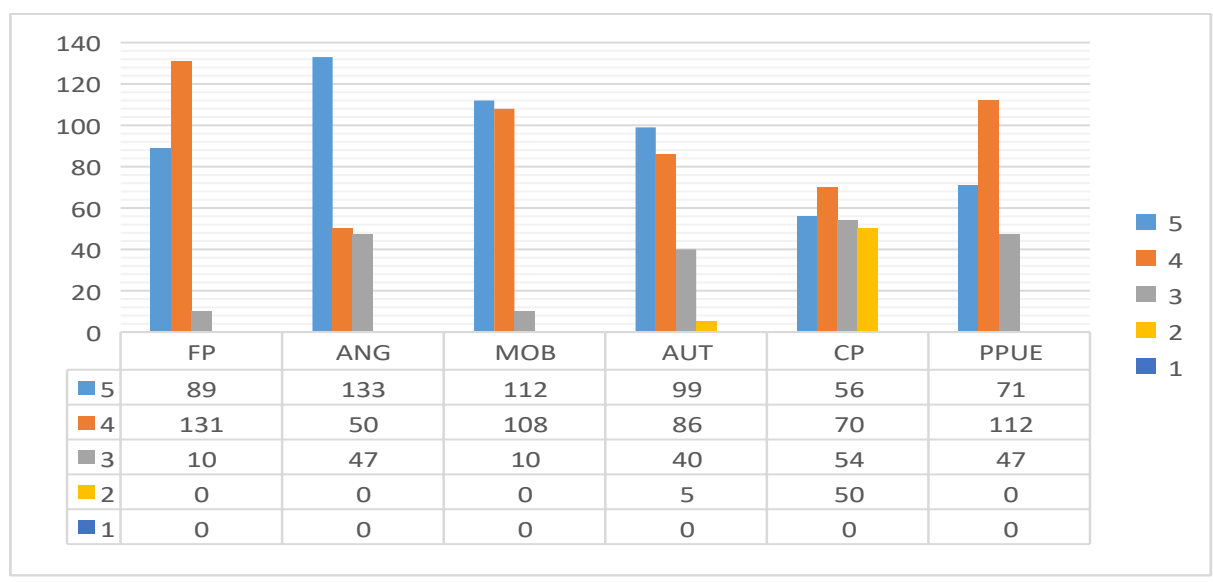

Figure 2: The importance of the manager in the school organization

Source: by the author

Number of observations where there have been most negative scores is for its the fully contracts with businesses, NGOs and other organizations on ongoing projects (50, respectively). Most of the cases in which the influence was perceived to be of great value were the selection, employment and termination of employment relationships of the personnel of the unit, as well as the selection of the non-teaching staff, followed by the mobility of the teaching staff and obtaining the authorizations and legal notices necessary for the functioning of the unit. of education.

The results show that in all the answers received there is at least one attribution that has been evaluated as having minimal influence. The conclusion of contracts with the economic agents, NGOs and other organizations regarding the development of the projects was evaluated negatively by the majority of the respondents, as it has no influence on the performance increase. In most of these cases, the results suggest the negative influence in the context of their own work. However, there are two aspects that require a separate discussion, the hiring and mobility of teachers.

\section{Conclusion}

The management of the school institution must fulfill a catalyst role among the teaching staff, in the sense of promoting, identifying, stimulating and rewarding the creative teachers who participate in forming a positive image and increasing the prestige of the school within the community by creating its own organizational culture.

The school manager has to play a very important role, which must adopt a democratic leadership style and which must mobilize all the personnel in order to implement the change plan.

The elaboration of creative management strategies, with a high degree of applicability, implies the creation of a climate that encourages the creative behaviour of the teachers.

The ideal manager would be one who knows how to combine certain traits of a professional manager such as order and discipline with entrepreneurial characteristics such as rapid reaction to business opportunities, creativity and the ability to inspire employees with a sense of vision and challenge.

The managerial function represents a practical professional activity, for the exercise of which specific, technical and relational knowledge and skills are required. The professional training of the manager is essential for the development of the organization. It is the way to the performance of the organization. As managers work to become efficient, they raise the level of performance of the entire organization. Under the current conditions, the organization depends - for its functioning and survival - on the efficiency with which it is piloted, on the performance and managerial results. 


\section{Acknowledgements}

This paper was co-financed from the Human Capital Operational Program 2014-2020, project number POCU / 380/6/13/125245 no. 36482 / 23.05.2019 "Excellence in interdisciplinary PhD and post-PhD research, career alternatives through entrepreneurial initiative (EXCIA)", coordinator "The Bucharest University of Economic Studies".

\section{References}

Cojocaru, V. \& Slutu, L., (2007). Educational management. The Book of Moldova, Chisinau.

Gherguț, A., (2007), General and strategic management in education, Polirom, Iași.

Harrington, HJ, (2000). Total management in the company of the 21st century. Teora, Bucharest.

Harshman, CL., (2009), Decoding behavior to improve results: Using iWAM to unlock motivational and attitudinal patterns. The Institute for Work Attitude \& Motivation.

Jackson, DN MAB-II (2008). Multidimensional Aptitude Battery. Adapted by Dragoş Iliescu and Florian Glinţa. Ed Synapsis, Cluj-NapocA.

Kiel, F., \& Lennick, D., (2005). Moral intelligence - Enhancing business performance and leadership success.Pearson Education, Upper Saddle River, New Jersey.

Molan, V. (2005). A respected nation has quality education. In: Academic news, year. V, no. 3, Bucharest.

Nicolescu, O., Burduş, E., Zorlenţan, T. et alii. (1992). Management. Didactic and Pedagogical Publishing House, Bucharest.

Purkey \& Simth (1983). Adjoins the Romanian Institute of Educational Management (2003), Educational Management. CDMRO Publishing House, Iasi.

Sackney, L. (2007), History of the school effectiveness and improvement movement in Canada over the past 25 years International Handbook of School Effectiveness and Improvement. T. Townsend,

Verboncu I., Zalman M. (2005). Management and performance. University Publishing House, Bucharest. 